\title{
Retrograde Pyelogram
}

National Cancer Institute

\section{Source}

National Cancer Institute. Retrograde Pyelogram. NCI Thesaurus. Code C28654.

X-ray images of the ureters and kidneys obtained by injection of a radioopaque substance into the ureter, usually done via a cystoscope. 